\title{
Diosmetin inhibits cell proliferation and induces apoptosis by regulating autophagy via the mammalian target of rapamycin pathway in hepatocellular carcinoma HepG2 cells
}

\author{
JIE LIU* , HAO REN*, BIN LIU, QINGYU ZHANG, MINGYI LI and RUNZHI ZHU \\ Laboratory of Hepatobiliary Surgery, Affiliated Hospital of Guangdong Medical University, \\ Zhanjiang Key Laboratory of Hepatobiliary Diseases, Zhanjiang, Guangdong 524001, P.R. China
}

Received August 24, 2015; Accepted August 26, 2016

DOI: $10.3892 / \mathrm{ol} .2016 .5301$

\begin{abstract}
Hepatocellular carcinoma (HCC), which is a type of malignant tumor, is the fifth most common cancer in men and ninth in women worldwide. The aim of the present study was to investigate the antitumor effect of diosmetin (DIOS) in hepatocellular carcinoma HepG2 cells. The proliferation, apoptosis and autophagy rates of HepG2 cells were measured following treatment with DIOS. The effects of DIOS treatment on HepG2 cell proliferation and apoptosis rates were analyzed using MTT assays and Annexin V staining, respectively. The effect of DIOS treatment on autophagy levels was assessed using transmission electron microscopy, green fluorescent protein (GFP)-microtubule-associated protein 1 light chain (LC3) transfection and LysoTracker Red staining. Furthermore, bafilomycin A1 (BA1), an autophagy inhibitor, was used to assess the association between DIOS and cell autophagy, proliferation and apoptosis. In addition, the expression of autophagy-related proteins [mammalian target of rapamycin (mTOR), phosphatidylinositol 3-kinase, P70S6K, phosphoinositide-dependent kinase-1, extracellular signal-regulated kinase, 5'-AMP-activated protein kinase and $\mathrm{Akt}$ ] and apoptosis-related proteins [B-cell lymphoma (Bcl)-2-associated X protein, Bak, p53, Bcl-2 and caspase-3] were analyzed by western blotting. The results revealed that DIOS significantly inhibited proliferation $(\mathrm{P}<0.01)$ and induced apoptosis $(\mathrm{P}<0.001)$ in HepG2 cells. It was also demonstrated that DIOS triggered autophagy by regulating
\end{abstract}

Correspondence to: Dr Runzhi Zhu or Dr Mingyi Li, Laboratory of Hepatobiliary Surgery, Affiliated Hospital of Guangdong Medical University, Zhanjiang Key Laboratory of Hepatobiliary Diseases, 57 South Renmin Road, Zhanjiang, Guangdong 524001, P.R. China E-mail: hepatolab@gmail.com

E-mail: hepatolab@163.com

*Contributed equally

Key words: diosmetin, hepatocellular carcinoma, apoptosis, autophagy, mammalian target of rapamycin the mTOR pathway in HepG2 cells. Notably, following treatment of HepG2 cells with the autophagy inhibitor, BA1, the expression of apoptosis-related proteins, including Bax, Bak and p53, were significantly decreased $(\mathrm{P}<0.05)$, and cell viability was recovered to a certain extent. In conclusion, DIOS inhibits cell proliferation and induces apoptosis in HepG2 cells via regulation of the mTOR pathway. Thus, the results of the current study indicate that DIOS may present a potential therapeutic agent for HCC treatment.

\section{Introduction}

Hepatocellular carcinoma (HCC) is a relatively common type of malignant tumor in some less developed regions, especially in Eastern Asia (1,2). In 2012, it was estimated that HCC was the fifth most common type of cancer in males, accounting for $7.5 \%$ of all cancers, and the ninth most common type of cancer in females, accounting for $3.4 \%$ of all cancers (2). HCC exhibits one of the highest mortality rates among malignant tumors worldwide (the ratio of mortality to incidence is 0.95 ) and a low 5-year survival rate $(4.26 \%)$ when compared with other cancer types $(3,4)$. Because of the lack of specific symptoms in the early stage, a large proportion of patients are not diagnosed with HCC patients until metastasis has occurred (5). At present, common clinical and pathological parameters, including $\alpha$-fetoprotein and tumor differentiation, are used to diagnose HCC, and hepatectomy is combined with chemotherapy as the standard treatment (1). However, treatment is often ineffective due to the high incidence of recurrence and metastasis (6), and, thus, it is important to develop an effective novel therapeutic strategy to treat $\operatorname{HCC}(7,8)$.

Autophagy and apoptosis are two processes that remove aged or altered cells from the body (9). Autophagy is an evolutionarily conserved catabolic process that occurs in eukaryotic cells, which results in the lysosomal breakdown of organelles in response to stressful stimuli (10). It has previously been reported that anticancer therapies including cytotoxic chemotherapy, (11) radiation (12) and kinase inhibitors (13), are able to induce autophagy in tumors and cause cell death in tumor tissues. Apoptosis, also termed programmed cell death, is a complex process that is associated with the expression of apoptosis-related proteins, including p53, caspases, Bcl-2 
and Bax (14). Cell apoptosis may be induced due as a result of physiological regulation and chemical stimulation (7).

Diosmetin (DIOS; Fig. 1A), which is obtained from the legume Acacia farnesiana and the leaves of Olea europaea L., is an aglycone of the flavonoid glycoside, diosmin (15). DIOS has been demonstrated to exhibit antibacterial (16), antimicrobial (17), anti-inflammatory (18) and antioxidant (19) effects. Additionally, it has been demonstrated that DIOS exhibits anticancer activity in breast cancer cells by inducing cell cycle arrest (20). The present study aimed to investigate the effect of DIOS treatment on cell invasion and autophagy in HCC cells and to evaluate whether DIOS treatment triggers cell apoptosis.

\section{Materials and methods}

Reagents. DIOS (Sigma-Aldrich; Merck Millipore Darmstadt, Germany) was dissolved in $10 \mathrm{mg} / \mathrm{ml}$ dimethylsulfoxide (DMSO), diluted in RPMI-1640 medium (Thermo Fisher Scientific, Inc., Waltham, MA, USA) and stored at $-20^{\circ} \mathrm{C}$ in the dark prior to use. MTT was purchased from Amresco LCC (Solon, OH, USA) and the fluorescein isothiocyanate (FITC)-Annexin V Apoptosis Detection kit I was obtained from BD Biosciences (Franklin Lakes, NJ, USA). LysoTracker Red was purchased from Beyotime Institute of Biotechnology (Haimen, China) and the green fluorescent protein (GFP)microtubule-associated protein 1 light chain (LC3) plasmid was provided by the Institute of Neurology, Guangdong Medical College (Guangdong, China). Lipofectamine ${ }^{\mathrm{TM}} 2000$ transfection reagent was purchased from Thermo Fisher Scientific, Inc. Antibodies targeting Bak (cat. no. 12105), B-cell lymphoma-2 (Bcl-2; cat. no. 2876S), Bcl-2-associated X protein (Bax; cat. no. 2772S), p53 (cat. no. 9282S), caspase-3 (cat. no. 9665), LC3 (cat. no. 12741), Beclin-1 (cat. no. 4122S), mammalian target of rapamycin (mTOR; cat. no. 2972), phosphorylated (p)-mTOR (cat. no. 5536), phosphatidylinositol 3-kinase (PI3K p85, cat. no. 4257; PI3K p110, cat. no. 4255), phosphoinositide-dependent kinase-1 (PDK1; cat. no. 13037), Akt (cat. no. 9272), p-Akt (cat. no. 13038), extracellular signal-regulated kinase (ERK; cat. no. 4695S), p-ERK (cat. no. 4377S), 5'-AMP-activated protein kinase (AMPK; cat. no. 2795S), p-AMPK (cat. no. 2537), p70-S6 kinase (S6k; cat. no. 2708), p-S6k (cat. no. 9234) and GAPDH (cat. no. 2118) were purchased from Cell Signaling Technology, Inc. (Danvers, MA, USA). All antibodies were diluted to 1:1,000. Bafilomycin A1 (BA1) was purchased from Sigma-Aldrich; Merck Millipore.

Cell culture. The human HCC HepG2 cell line was provided by the Shanghai Maternal and Child Health Hospital (Shanghai, China). Cells were maintained in RPMI-1640 medium supplemented with $10 \%$ fetal bovine serum (Gibco; Thermo Fisher Scientific, Inc.), cultured at a $37^{\circ} \mathrm{C}$ in an atmosphere of $5 \%$ $\mathrm{CO}_{2}$, and passaged to $80 \%$ confluence.

Cell proliferation assay. Cell proliferation was assessed by MTT assay. A total of $1 \times 10^{4}$ cells/well were seeded in $100 \mu \mathrm{l}$ RPMI-1640 culture medium in a 96-well plate. Following $24 \mathrm{~h}$ in adhesive culture, the medium was removed and 1, 2, 5, 10, 15 or $20 \mu \mathrm{g} / \mathrm{ml}$ DIOS was added. Untreated cells served as the control group. After $24 \mathrm{~h}, 20 \mu \mathrm{l}$ MTT $(5 \mathrm{mg} / \mathrm{ml})$ was added to each well. Following incubation for $3 \mathrm{~h}$ at $37^{\circ} \mathrm{C}$, the medium was removed and $200 \mu 1 \mathrm{DMSO}$ was added to each well. Subsequently, absorbance was measured using a microplate reader (PerkinElmer, Inc., Waltham, MA, USA) at a wavelength of $570 \mathrm{~nm}$. Each experiment was performed in triplicate.

Annexin V staining. Annexin V staining was used to assess the apoptotic rate of HCC cells following treatment with DIOS. The Annexin V Apoptosis Detection kit I was used, according to the manufacturer's instructions. Briefly, cells (5x10 $/$ well) were seeded into a 6 -well plate at $37^{\circ} \mathrm{C}$ overnight followed by treatment with 5,10 and $20 \mu \mathrm{g} / \mathrm{ml}$ DIOS. Untreated cells served as the control. Cells were washed twice with cold phosphate-buffered saline (PBS) and resuspended in $100 \mu \mathrm{l}$ binding buffer. The cell suspensions were then treated with $5 \mu \mathrm{l}$ FITC-Annexin $\mathrm{V}$ and $10 \mu \mathrm{l}$ propidium iodide (PI) and incubated for $15 \mathrm{~min}$ at room temperature in the dark. Next, $400 \mu \mathrm{l}$ binding buffer was added to terminate the reaction and the apoptosis rate of the cells was analyzed by flow cytometry (BD FACSCanto II; BD Biosciences) at a 488-nm excitation wavelength; the emission wavelengths of FITC and PI were observed at $520 \mathrm{~nm}$ and $617 \mathrm{~nm}$, respectively.

Transmission electron microscopy. Cells $\left(1 \times 10^{6}\right)$ were fixed in $2.5 \%$ glutaraldehyde (Ted Pella Inc., Redding, CA, USA) and $0.1 \mathrm{~mol} / 1$ phosphate buffer ( $\mathrm{pH} 7.4$; Jinuo, Hangzhou, China) for $30 \mathrm{~min}$ at room temperature followed by fixation in $1 \%$ osmium tetraoxide (Ted Pella Inc.) and $0.1 \mathrm{~mol} / 1$ phosphate buffer ( $\mathrm{pH}$ 7.4) for $30 \mathrm{~min}$. Cells were then subjected to graded ethanol dehydration with epoxy propane (Ted Pella Inc.), embedded in epoxy resin and segmented using a UC7 ultrastructural slicer (Leica Microsystems GmbH, Wetzlar, Germany). Sections (90-nm) were subsequently stained with 5\% uranyl acetate (SPI-Chem, West Chester, PA, USA) and $5 \%$ lead citrate (SPI-Chem) prior to analysis using a JEM1400 transmission electron microscope (JEOL Ltd., Tokyo, Japan).

Cell transfection. Cells at $80 \%$ confluence were seeded in 6 wells plate and transfected with the GFP-LC3 plasmid using Lipofectamine $^{\mathrm{TM}} 2000$, according to the manufacturer's instructions. Cells were treated with various concentrations $(0,5,10$ and $20 \mu \mathrm{g} / \mathrm{ml})$ of DIOS $24 \mathrm{~h}$ after transfection and assessed using a fluorescence microscope (Leica Microsystems $\mathrm{GmbH}$ ). Green fluorescence indicated that plasmids had successfully been transfected into the cells.

Lyso-Tracker Red staining. Cells were treated with 0, 5, 10 and $20 \mu \mathrm{g} / \mathrm{ml}$ DIOS for $24 \mathrm{~h}$ followed by incubation with $75 \mathrm{nmol} / 1$ Lyso-Tracker Red for 2-3 h at $37^{\circ} \mathrm{C}$. Next, LysoTracker Red was removed and cells were stained with Hoechst 33342 (Beyotime Institute of Biotechnology) for $10 \mathrm{~min}$ at $37^{\circ} \mathrm{C}$. Cells were washed three times in PBS, incubated with fresh culture medium and observed using a fluorescence microscope (Leica Microsystems GmbH). Red fluorescence was measured using $544 \mathrm{~nm}$ excitation and $590 \mathrm{~nm}$ long pass emission filters.

Western blotting. Cells were washed twice with PBS and suspended in lysis buffer (Beyotime Institute of Biotechnology) for $30 \mathrm{~min}$ on ice. Lysates were centrifuged at $13,000 \mathrm{x} g$ for $10 \mathrm{~min}$ at $4^{\circ} \mathrm{C}$ and transferred to polyvinylidene difluoride 
membranes (EMD Millipore, Billerica, USA) prior to $10 \%$ SDS-PAGE. Membranes were then blocked with 5\% bovine serum albumin (Biosharp, Hefei, China) in Tris-buffered saline (Beyotime Institute of Biotechnology) containing Tween-20 (TBST; Sangon Biotech Co., Ltd., Shanghai, China) for $1 \mathrm{~h}$ at room temperature. After three washes with TBST, membranes were incubated with primary antibodies at $4^{\circ} \mathrm{C}$ overnight. Membranes were then washed three times with TBST prior to incubation with secondary antibody (cat. no. E030120; 1:1,000; EarthOX Life Sciences, Millbrae, CA, USA) for $2 \mathrm{~h}$ at room temperature. The protein bands were exposed in a dark room and analyzed using AlphaView SA 3.4.0. software (ProteinSimple, San Jose, CA, USA). Protein expression was normalized to GAPDH.

Statistical analysis. Data were obtained from at least three independent experiments and all results are expressed as the mean \pm standard error of the mean. Differences between the groups were assessed using the Student's t-test and all statistical analysis was performed using SPSS 18.0 statistical software (SPSS, Inc., Chicago, IL, USA). P $<0.05$ was considered to indicate a statistically significant difference.

\section{Results}

DIOS inhibits HepG2 cell proliferation. MTT assay was performed to assess the effect of DIOS on HepG2 cell proliferation. The results demonstrated that cell proliferation was significantly inhibited following treatment with $\geq 5 \mu \mathrm{g} / \mathrm{ml}$ DIOS ( $\mathrm{P}<0.01$; Fig. 1B) with a half maximal inhibitory concentration of $11.60 \pm 1.71 \mu \mathrm{g} / \mathrm{ml}$ at $24 \mathrm{~h}$. In addition, morphological changes were observed under a microscope: Cells treated with 10 and $20 \mu \mathrm{g} / \mathrm{ml}$ DIOS were distorted and cell proliferation was markedly inhibited compared with controls (Fig. 1C).

DIOS promotes apoptosis via activation of caspase-3 in HepG2 cells. FITC-Annexin V/PI double staining was used to detect apoptosis in HepG2 cells following DIOS treatment. Following treatment with 10 and $20 \mu \mathrm{g} / \mathrm{ml}$ DIOS, the rate of apoptosis significantly increased compared with the control $(25.6 \pm 4.8$ and $37.6 \pm 6.1$ vs. $8.8 \pm 0.7$, respectively; $\mathrm{P}<0.001$; Fig. 2A). These results indicated that DIOS treatment promotes apoptosis in HepG2 cells in a dose-dependent manner. Furthermore, western blot analysis demonstrated that DIOS downregulated Bcl-2 expression and upregulated Bak, Bax, $\mathrm{p} 53$ and casapse- 3 protein expression in a dose-dependent manner (Fig. 2B).

DIOSinducesautophagyin HepG2 cells. Transmission electron microscopy demonstrated that DIOS induced the generation of autophagosomes in HepG2 cells. As shown in Fig. 3A, cells treated with $5 \mu \mathrm{g} / \mathrm{ml}$ DIOS exhibited enlarged mitochondria and fragmented cristae. Cells treated with $\geq 10 \mu \mathrm{g} / \mathrm{ml}$ DIOS exhibited increased numbers of autophagosomes in the cytoplasm. To confirm the progression of autophagy, the distribution of GFP-LC3 was detected following transfection of the GFP-LC3 plasmid into the cytoplasm. The cytosolic form (LC3-I), viewed as dispersed green fluorescence under the microscope, is converted to the autophagosome-associating form (LC3-II), viewed as bright fluorescent spots under the microscope, as autophagy occurs (21). Following treatment of cells with $0,5,10$ and $20 \mu \mathrm{g} / \mathrm{ml}$ DIOS for $24 \mathrm{~h}$, the GFP-LC3 in the cytoplasm changed from the cytosolic form into the autophagosome-associating form (Fig. 3B), indicating that DIOS treatment converted LC3-I to LC3-II, which is associated with the formation of autophagosomes. In addition, LysoTracker Red staining was used to count the number of lysosomes in the HepG2 cells following treatment with DIOS. The results revealed that the number of active lysosomes in HepG2 cells increased in a dose-dependent manner following DIOS treatment (Fig. 3C). These results indicated that DIOS induced cell autophagy in HepG2 cells in a dose-dependent manner.

DIOS induces cell autophagy via the mTOR-related signaling pathway. mTOR and proteins associated with the signaling pathway, including PI3K, PDK1, Akt, ERK1/2, AMPK S6k and Beclin-1, are autophagy regulatory proteins $(22,23)$. LC3-II is critical for autophagosome formation and thus is a marker of autophagy (24). In the current study, expression of the aforementioned proteins in HepG2 cells was measured to evaluate whether the autophagy mechanism was induced following DIOS treatment. Western blot analysis revealed that following treatment with DIOS for $24 \mathrm{~h}, \mathrm{LC} 3-\mathrm{II}$ and Beclin-1 expression increased in a dose-dependent manner (Fig. 3D). In addition AMPK protein expression was significantly increased $(\mathrm{P}<0.001)$ and mTOR, PI3K p85 and S6k protein expression were significantly decreased in a dose-dependent manner $(\mathrm{P}<0.05$; Fig. 4). No marked changes in the expression of Akt and ERK1/2 were observed ( $P>0.05)$; however, the phosphorylation of Akt and ERK1/2 were significantly decreased $(\mathrm{P}<0.001$; Fig. 4).

Autophagy inhibitor BA1 reverses DIOS-induced cell proliferation inhibition and apoptosis. To determine the effect of DIOS-induced autophagy, HepG2 cells were treated with BA1 to attenuate the autophagy process. The results revealed that treatment with DIOS alone resulted in significantly decreased cell proliferation when compared with cells treated with DIOS and BA1 (Fig. 5A and B). Furthermore, western blotting demonstrated that the expression of pro-apoptosis proteins Bak, Bax and p53 was higher following treatment with DIOS alone when compared with combined treatment with DIOS and BA1 (Fig. 5C and D).

\section{Discussion}

HCC is one of the most common malignant tumors worldwide, accounting for the second highest number of cancer-associated mortalities $(9.1 \%$ of all cancer-associated deaths); the mortality rate reached $95 \%$ in $2012(2,3)$. It has been reported that several flavonoid compounds, including baicalein $(25)$, dihydromyricetin $(26,27)$ and resveratrol $(28)$ may exhibit antitumor effects. DIOS is a flavonoid that has been demonstrated to exhibit antibacterial, antimicrobial, anti-inflammatory and antioxidant effects (29). Previously, it has been demonstrated that DIOS induces cell cycle arrest in the G2/M phase (30); however, the association between DIOS and cell proliferation inhibition, apoptosis and autophagy in HCC cells remains unclear. 
A<smiles>COc1ccc(-c2cc(=O)c3c(O)cc(O)cc3o2)cc1O</smiles>

C Control

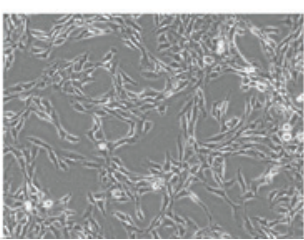

B
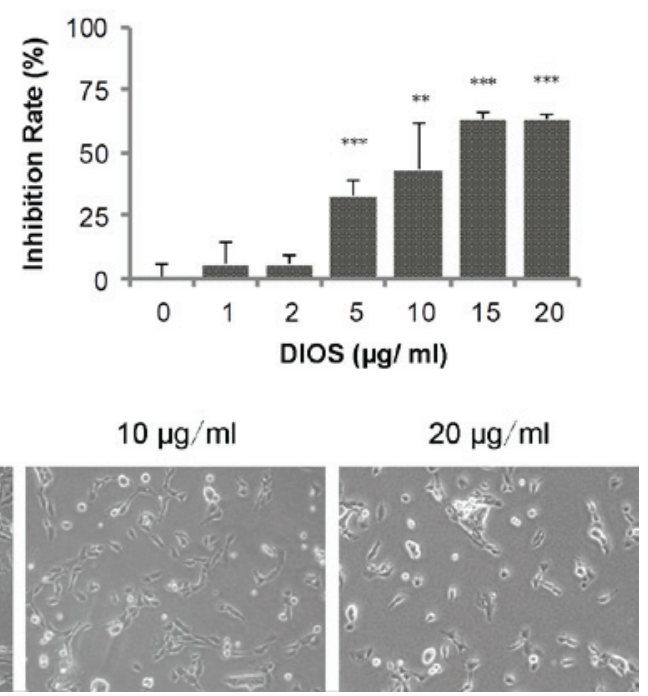

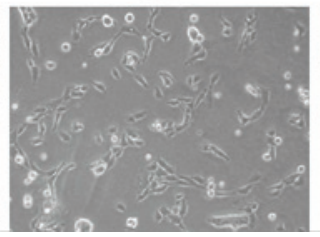

$20 \mu \mathrm{g} / \mathrm{ml}$

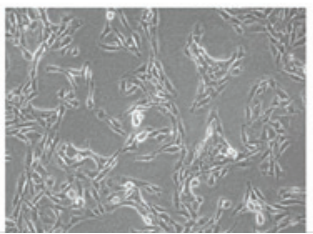

Figure 1. DIOS inhibits proliferation of HepG2 cells. (A) Chemical structure of DIOS. (B) DIOS treatment for $24 \mathrm{~h}$ inhibited of cell proliferation in a dose-dependent manner. (C) The morphology of HepG2 cells following treatment with different concentrations of DIOS. Data are presented as the mean \pm standard error of the mean. ${ }^{* *} \mathrm{P}<0.01$ and ${ }^{* * *} \mathrm{P}<0.001$ vs. control. DIOS, diosmetin.

A
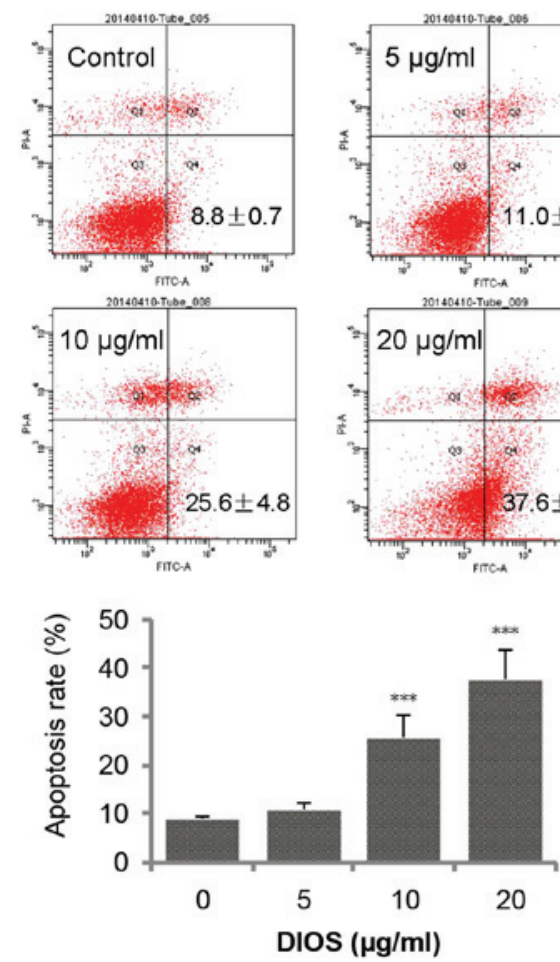

B
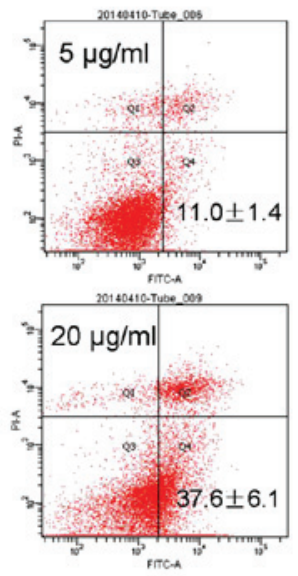

Caspase-3

$35 \mathrm{kDa}$

$19 \mathrm{kDa}$

$17 \mathrm{kDa}$

GAPDH

DIOS

$\mu \mathrm{g} / \mathrm{ml}$

Bak

Bax

Bcl-2
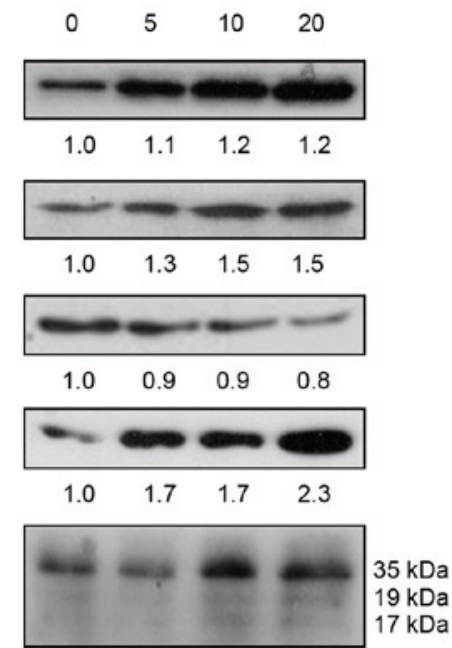

$\begin{array}{llll}1.0 & 1.0 & 1.2 & 1.2\end{array}$

$\begin{array}{llll}1.0 & 1.0 & 1.2 & 1.2\end{array}$

$\begin{array}{llll}1.0 & 1.0 & 1.1 & 1.1\end{array}$

Figure 2. DIOS promotes apoptosis in HepG2 cells via activation of caspase-3. (A) Flow cytometry revealing that the apoptosis rate of HepG2 cells increased following treatment with DIOS treatment in a dose-dependent manner. ${ }^{* * *} \mathrm{P}<0.001$. vs. control. (B) Western blot analysis demonstrating the expression of apoptosis-related proteins. The expression of Bak, Bax, p53 and caspase- 3 was increased and Bcl-2 was decreased in cells treated with DIOS. Data are presented as the mean \pm standard error of the mean. DIOS, diosmetin; GAPDH, glyceraldehyde 3-phosphate dehydrogenase; Bcl-2 B-cell lymphoma-2; Bax, B-cell-associated X protein.

Apoptosis induction is considered to be an effective strategy for cancer treatment (27). The present study indicated that exposing HepG2 cells to $>5 \mathrm{ug} / \mathrm{ml}$ DIOS for $24 \mathrm{~h}$ significantly inhibited cell proliferation Furthermore, treatment with 10 and $20 \mu \mathrm{g} / \mathrm{ml}$ DIOS also increased apoptosis rates in HepG2 cells via the upregulation of apoptosis-related proteins, $\mathrm{p} 53$ and $\mathrm{Bak}$, alteration of the $\mathrm{Bax} / \mathrm{Bcl}-2$ ratio and subsequent activation of caspase-3. p53 is one of the most important proteins involved in the death receptor and mitochondrial pathways (26). It regulates the expression of 
A Control

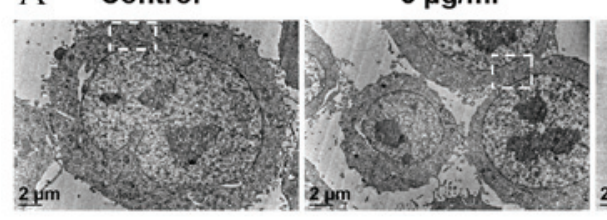

$10 \mu \mathrm{g} / \mathrm{ml}$

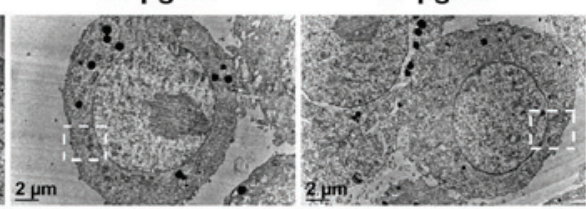

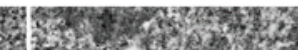

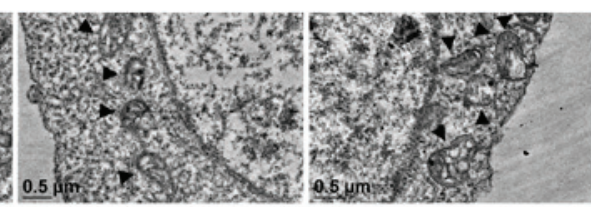

B
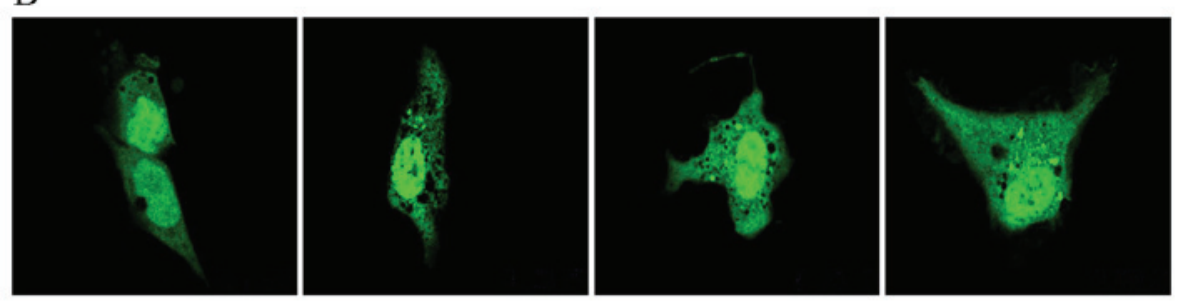

C
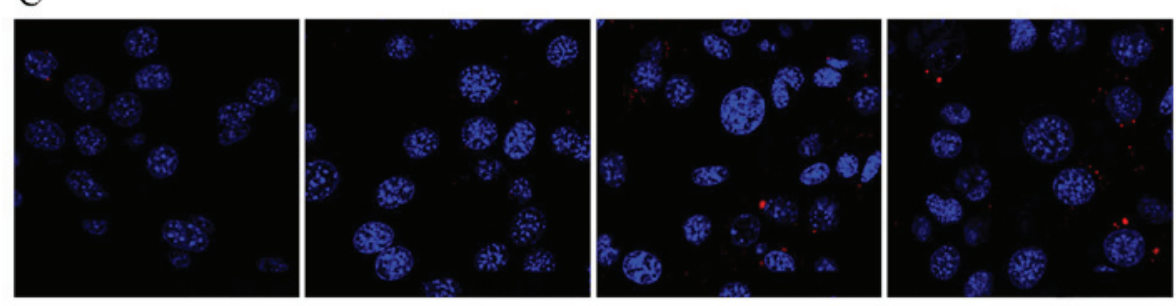

$\mathrm{D}$
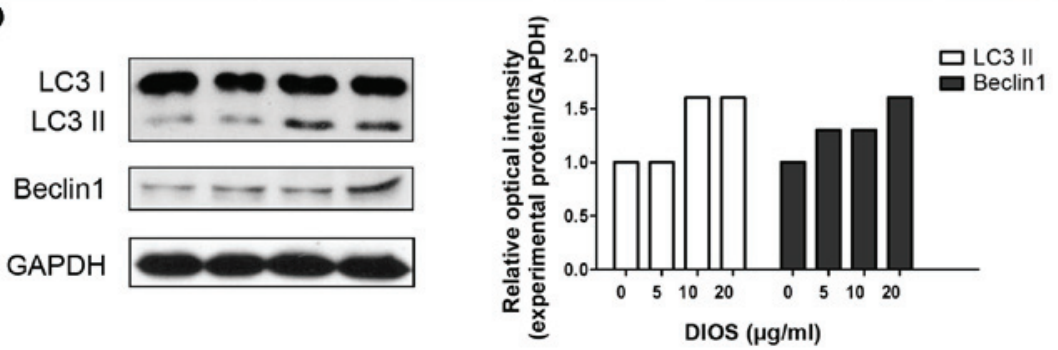

Figure 3. DIOS induces autophagy in HepG2 cells. (A) The electron-microscopy images of HepG2 cells following DIOS treatment. Upper panels show the whole cells (magnification, x8,000) and lower panels show enlarged images of the white boxes in the upper panels (magnification, $\mathrm{x} 4,000$ ), highlighting the mitochondria and autophagosomes. Black arrows in the lower panels indicate autophagosomes observed in cytoplasm. (B) LC3II expression in HepG2 cells increased following treatment with $0,5,10$ and $20 \mu \mathrm{g} / \mathrm{ml}$ DIOS. Cells were transfected with GFP-LC3 plasmid and treated with different concentration of DIOS $(0,5,10$ or $20 \mu \mathrm{g} / \mathrm{ml})$ for $24 \mathrm{~h}$. It was observed that the GFP-LC3 protein was converted from the LC3-I to LC3-II in a dose-dependent manner following DIOS treatment (magnification, x1,260). (C) Confocal microscopy images of the LysoTracker Red test. HepG2 cells were treated with 0, 5, 10 and $20 \mu$ g/m1 DIOS for $24 \mathrm{~h}$. Red coloring indicates the presence of lysosomes (magnification, x630). (D) Western blot analysis revealing LC3II and Beclin1 protein expression levels in HepG2 cells following treatment with $0,5,10$ and $20 \mu \mathrm{g} / \mathrm{ml}$ DIOS for $24 \mathrm{~h}$ (scale bars=50 $\mu \mathrm{m}$ ). DIOS, diosmetin; GAPDH, glyceraldehyde 3-phosphate dehydrogenase; LC3, microtubule-associated protein 1.

Bax, Bak and Bcl-2 and converts pro-caspase-3 into cleaved caspase-3 to stimulate apoptosis (8). Bax is a pro-apoptotic protein, which relocates to the mitochondria following the induction of apoptosis to induce mitochondria depolarization. By contrast, $\mathrm{Bcl}-2$ is an anti-apoptotic protein that inhibits the function of Bax (31). Therefore, the ratio of Bax/Bcl-2 is associated with apoptosis (32). The current study indicated that DIOS induces HepG2 cell apoptosis by upregulating the protein expression of Bax and downregulating $\mathrm{Bcl}-2$ protein expression.

Autophagy is a degradation process that delivers cytoplasmic material to lysosomes via autophagosomes. Autophagy is considered to exhibit two separate effects on tumor development: It has the ability to suppress the growth of precancerous cells and maintain a stable genome and it may also prevent the survival of tumor cells (33). Therefore, whether autophagosomes protect cancer cells from external factors or induce cell apoptosis in cancer therapy remains controversial (34). Previous studies have indicated that pharmacological inhibition of autophagy or silencing of autophagy related genes, such as $A T G 5$, may reduce the risk of drug resistance arising following chemotherapy treatment (35-37). It has been reported that autophagy induces cell death by depleting the cell of organelles and critical proteins, a process termed autophagic cell death (38-40). mTOR is considered a critical inhibitor protein in the regulation of autophagy; 


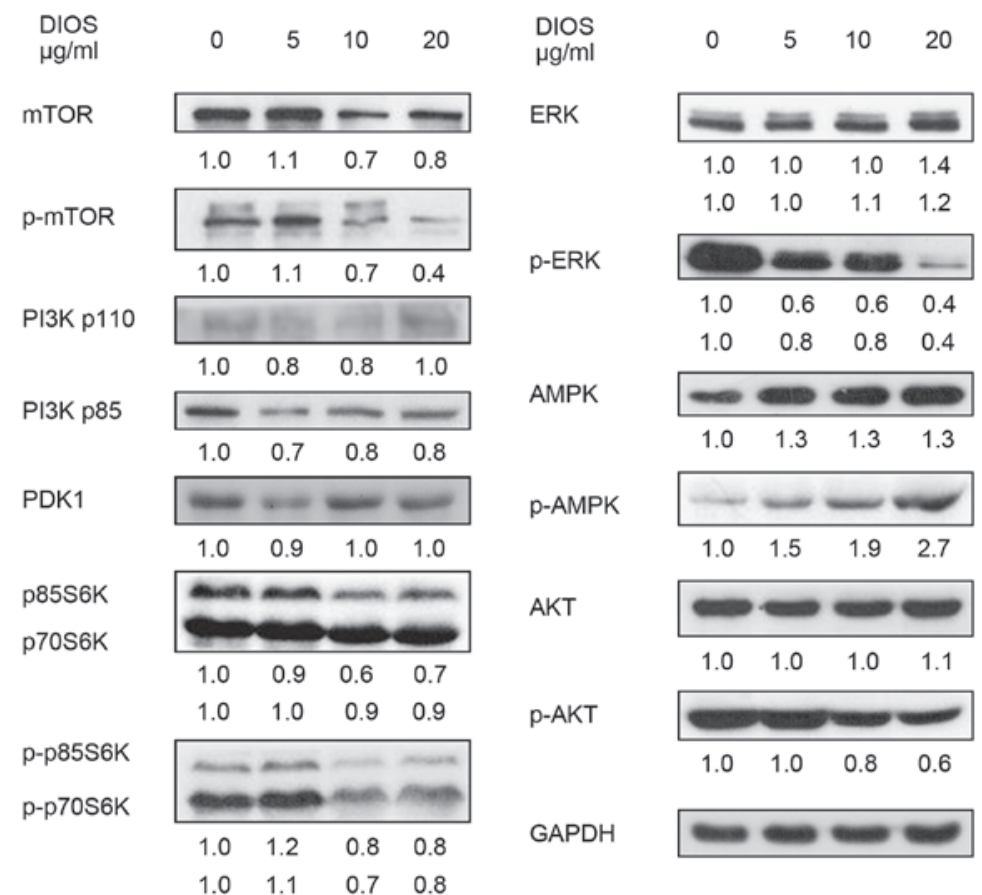

Figure 4. DIOS induces cell autophagy via the mTOR-related signaling pathway. Western blot analysis of proteins in the mTOR-related signaling pathway revealing that DIOS stimulates the mTOR-related signaling pathway to induce cell autophagy. DIOS, diosmetin; p, phosphorylated; mTOR, mammalian target of rapamycin; PI3K, phosphatidylinositide 3-kinase; PDK1, phosphoinositide-dependent kinase-1; S6K, s6 kinase; ERK, extracellular signal-regulated kinase; AMPK 5' AMP-activated protein kinase.

A

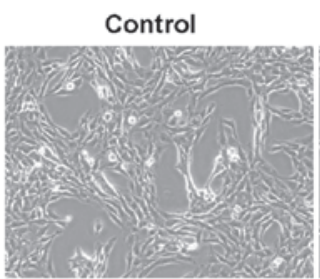

$\mathrm{C}$

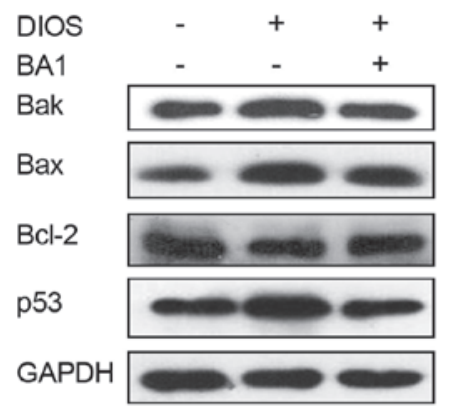

DIOS

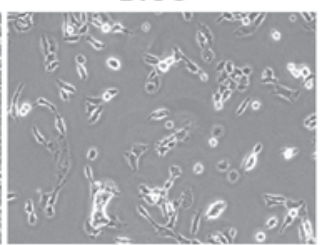

D
B

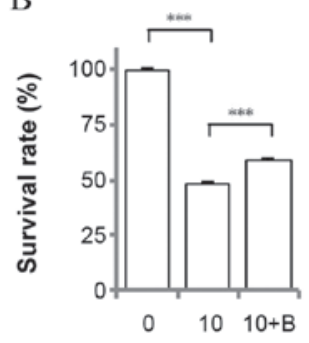

$\operatorname{DIOS}(\mu \mathrm{g} / \mathrm{ml})$
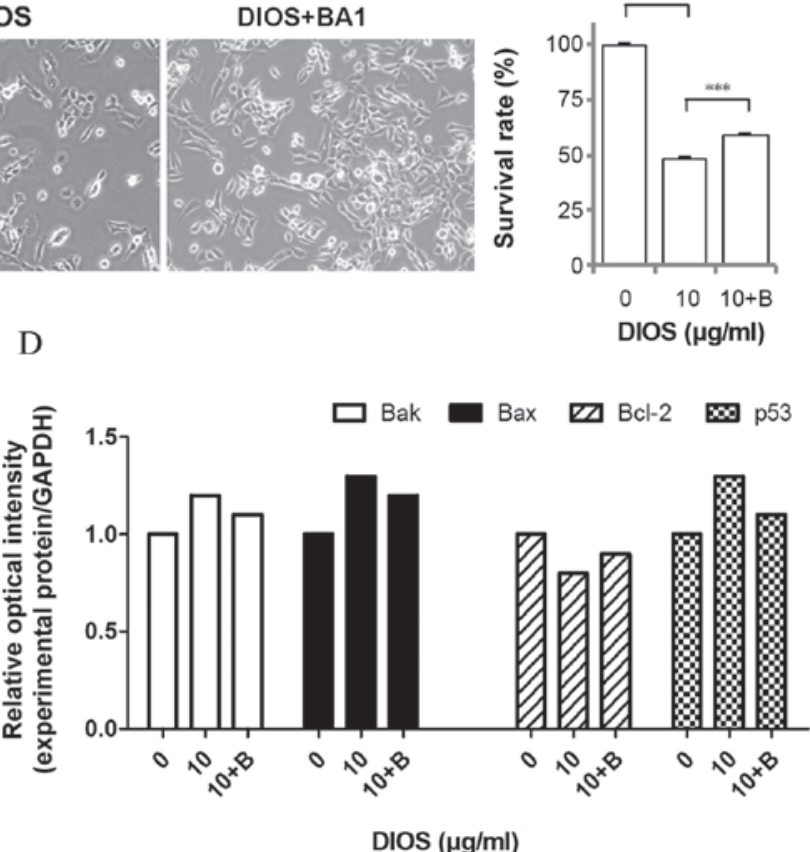

Figure 5. Cell viability was recovered and expression of apoptosis-related proteins were decreased following treatment with the autophagy inhibitor, BA1. (A) The morphology of HepG2 cells treated with $10 \mu \mathrm{g} / \mathrm{ml}$ DIOS either in the presence or absence of BA1. (B) The survival rate of cells treated with DIOS alone vs. with DIOS and BA1. (C) The level of expression of apoptosis-related proteins. (D) Analysis of relative optical intensity of the expression of different autophagy-related proteins. Data are presented as the mean \pm standard error of the mean. ${ }^{* * * *} \mathrm{P}<0.001$ vs. control. BA1, bafilomycin A1; DIOS, diosmetin; GAPDH, glyceraldehyde 3-phosphate dehydrogenase; Bcl-2 B-cell lymphoma-2; Bax, B-cell-associated protein X.

therefore, inhibition of mTOR is associated with triggering autophagy in tumor cells (41). Pathways that regulate mTOR expression include the PI3K/Akt (42), mitogen-activated protein kinase/ERK 1/2 (41) and the AMPK (43) pathways. mTOR activity is stimulated by Akt and ERK 1/2 phosphorylation and inhibited by AMPK phosphorylation. S6 kinase is 
another essential protein involved in mTOR phosphorylation and it has been suggested that $\mathrm{S} 6$ kinase negatively regulates autophagy (44).

The results of the present study indicated that DIOS does not affect Akt, Erk1/2 and AMPK expression, however, it was demonstrated that DIOS treatment decreased the phosphorylation of Akt and Erk1/2 and stimulated AMPK phosphorylation, subsequently inhibiting mTOR expression. Furthermore, DIOS suppressed the phosphorylation of S6 kinase, which also contributed to the inhibition of mTOR phosphorylation. We hypothesize that the DIOS-induced inhibition of mTOR expression and phosphorylation triggered autophagy in HepG2 cells.

Autophagy and apoptosis are important biological processes that maintain cell stability, structure, function and development (45). In the present study, autophagy was blocked by BA1 (41) to investigate whether DIOS-triggered apoptosis was affected. Notably, the inhibition of HepG2 cell proliferation caused by DIOS treatment was partially reversed and the expression of apoptosis-related proteins was altered: p53, Bak and Bax expression decreased, however, Bcl-2 expression increased marginally. Several studies have demonstrated that a number of molecules involved in autophagy are also involved in apoptosis signal transduction (46-48). For example, the autophagy-related protein Beclin-1 generates a pro-apoptotic protein fragment, which interacts with the mitochondrial apoptosis pathway via the Bcl-2 family (48). Furthermore, it has been demonstrated that $\mathrm{Bcl}-2$ functions as an anti-apoptotic protein and an anti-autophagy protein via its inhibitory interaction with Beclin-1 (49). However, the exact association between autophagy and apoptosis remains unclear and requires further investigation.

In conclusion, the present study demonstrated that DIOS effectively inhibits proliferation and induces apoptosis in HCC cells, and these effects were a result of autophagy induction via mTOR-related pathways. Therefore, DIOS may present a novel therapeutic treatment for HCC.

\section{Acknowledgements}

The present study was supported by The Zhanjiang Key Laboratory of Hepatobiliary Diseases (grant no. 2013A402-4), The Research Funding of Guangdong Medical University (grant no. M2014020) and the Yangfan Plan of Talents Recruitment Grant, Guangdong, China (grant no. YueRenCaiBan [2016] 6).

\section{References}

1. Mu H, Lin KX, Zhao H, Xing S, Li C, Liu F, Lu HZ, Zhang Z, Sun YL, Yan XY, et al: Identification of biomarkers for hepatocellular carcinoma by semiquantitative immunocytochemistry. World J Gastroenterol 20: 5826-5838, 2014.

2. Ferlay J, Soerjomataram I, Dikshit R, Eser S, Mathers C, Rebelo M, Parkin DM, Forman D and Bray F: Cancer incidence and mortality worldwide: Sources, methods and major patterns in GLOBOCAN 2012. Int J Cancer 136 E359-E386, 2015.

3. Jin Y, Chen J, Feng Z, Fan W, Wang Y, Li J and Tong D: The expression of Survivin and NF- $\kappa \mathrm{B}$ associated with prognostically worse clinicopathologic variables in hepatocellular carcinoma. Tumour Biol 35: 9905-9910, 2014.

4. Kim HY and Park JW: Clinical trials of combined molecular targeted therapy and locoregional therapy in hepatocellular carcinoma: Past, present and future. Liver cancer 3: 9-17, 2014
5. Chen L, Wu LL, Zhang ZL, Hu J, Tang M, Qi CB, Li N and Pang DW: Biofunctionalized magnetic nanospheres-based cell sorting strategy for efficient isolation, detection and subtype analyses of heterogeneous circulating hepatocellular carcinoma cells. Biosens Bioelectron 85: 633-640, 2016.

6. Mano Y, Aishima S, Kubo Y, Tanaka Y, Motomura T, Toshima T, Shirabe K, Baba S, Maehara Y and Oda Y: Correlation between biological marker expression and fluorine-18 fluorodeoxyglucose uptake in hepatocellular carcinoma. Am J Clin Pathol 142: 391-397, 2014.

7. Zhang QY, Li R, Zeng GF, Liu B, Liu J, Shu Y, Liu ZK, Qiu ZD, Wang DJ, Miao HL, et al: Dihydromyricetin inhibits migration and invasion of hepatoma cells through regulation of MMP-9 expression. World J Gastroenterol 20: 10082-10093, 2014.

8. Liu J, Shu Y, Zhang Q, Liu B, Xia J, Qiu M, Miao H, Li M and Zhu R: Dihydromyricetin induces apoptosis and inhibits proliferation in hepatocellular carcinoma cells. Oncol Lett 8: 1645-1651, 2014

9. Guglielmotto M, Monteleone D, Piras A, Valsecchi V, Tropiano M, Ariano S, Fornaro M, Vercelli A, Puyal J, Arancio O, et al: Abeta1-42 monomers or oligomers have different effects on autophagy and apoptosis. Autophagy 10: 1827-1843, 2014.

10. Kongsuphol P, Mukda S, Nopparat C, Villarroel A and Govitrapong $\mathrm{P}$ : Melatonin attenuates methamphetamine-induced deactivation of the mammalian target of rapamycin signaling to induce autophagy in SK-N-SH cells. J Pineal Res 46: 199-206, 2009.

11. Fu J, Shao CJ, Chen FR, Ng HK and Chen ZP: Autophagy induced by valproic acid is associated with oxidative stress in glioma cell lines. Neuro Oncol 12: 328-340, 2010.

12. Yao KC, Komata T, Kondo Y, Kanzawa T, Kondo S and Germano IM: Molecular response of human glioblastoma multiforme cells to ionizing radiation: Cell cycle arrest, modulation of cyclin-dependent kinase inhibitors, and autophagy. J Neurosurg 98: 378-384, 2003.

13. Ertmer A, Huber V, Gilch S, Yoshimori T, Erfle V, Duyster J, Elsässer HP and Schätzl HM: The anticancer drug imatinib induces cellular autophagy. Leukemia 21: 936-942, 2007.

14. Wu S, Liu B, Zhang Q, Liu J, Zhou W, Wang C, Li M, Bao S and Zhu R: Dihydromyricetin reduced Bcl-2 expression via $\mathrm{p} 53$ in human hepatoma HepG2 cells. PloS one 8: e76886, 2013.

15. Spanakis M, Kasmas S and Niopas I: Simultaneous determination of the flavonoid aglycones diosmetin and hesperetin in human plasma and urine by a validated GC/MS method: In vivo metabolic reduction of diosmetin to hesperetin. Biomed Chromatogr 23: 124-131, 2009.

16. Chan BC, Ip M, Gong H, Lui SL, See RH, Jolivalt C, Fung KP, Leung PC, Reiner NE and Lau CB: Synergistic effects of diosmetin with erythromycin against $\mathrm{ABC}$ transporter over-expressed methicillin-resistant Staphylococcus aureus (MRSA) RN4220/pUL5054 and inhibition of MRSA pyruvate kinase. Phytomedicine 20: 611-614, 2013.

17. Meng JC, Zhu QX and Tan RX: New antimicrobial mono-and sesquiterpenes from Soroseris hookeriana subsp. Planta Med 66: 541-544, 2000

18. Chandler D, Woldu A, Rahmadi A, Shanmugam K, Steiner N, Wright E, Benavente-García O, Schulz O, Castillo J and Münch G: Effects of plant-derived polyphenols on TNF-alpha and nitric oxide production induced by advanced glycation endproducts. Mol Nutr Food Res 54: (Suppl 2) S141-S150, 2010.

19. Liao W, Ning Z, Chen L, Wei Q, Yuan E, Yang J and Ren J: Intracellular antioxidant detoxifying effects of diosmetin on 2 , 2-azobis(2-amidinopropane) dihydrochloride (aaph)-induced oxidative stress through inhibition of reactive oxygen species generation. J Agric Food Chem 62: 8648-8654, 2014.

20. Androutsopoulos VP, Mahale S, Arroo RR and Potter G: Anticancer effects of the flavonoid diosmetin on cell cycle progression and proliferation of MDA-MB 468 breast cancer cells due to CYP1 activation. Oncol Rep 21: 1525-1528, 2009.

21. Kabeya Y, Mizushima N, Yamamoto A, Oshitani-Okamoto S, Ohsumi Y and Yoshimori T: LC3, GABARAP and GATE16 localize to autophagosomal membrane depending on form-II formation. J Cell Sci 117: 2805-2812, 2004.

22. Saiki S, Sasazawa Y, Imamichi Y, Kawajiri S, Fujimaki T, Tanida I, Kobayashi H, Sato F, Sato S, Ishikawa K, et al: Caffeine induces apoptosis by enhancement of autophagy via PI3K/Akt/mTOR/p70S6K inhibition. Autophagy 7: 176-187, 2011.

23. Hanahan D and Weinberg RA: Hallmarks of cancer: The next generation. Cell 144: 646-674, 2011. 
24. Mauthe M, Jacob A, Freiberger S, Hentschel K, Stierhof YD, Codogno P and Proikas-Cezanne T: Resveratrol-mediated autophagy requires WIPI-1-regulated LC3 lipidation in the absence of induced phagophore formation. Autophagy 7 : 1448-1461, 2011.

25. Chen H, Gao Y, Wu J, Chen Y, Chen B, Hu J and Zhou J: Exploring therapeutic potentials of baicalin and its aglycone baicalein for hematological malignancies. Cancer Lett 354: 5-11, 2014.

26. Zhang Q, Liu J, Liu B, Xia J, Chen N, Chen X, Cao Y, Zhang C, $\mathrm{Lu} \mathrm{C}$, Li M and Zhu R: Dihydromyricetin promotes hepatocellular carcinoma regression via a p53 activation-dependent mechanism. Sci Rep 4: 4628, 2014.

27. Zeng G, Liu J, Chen H, Liu B, Zhang Q, Li M and Zhu R: Dihydromyricetin induces cell cycle arrest and apoptosis in melanoma SK-MEL-28 cells. Oncol Rep 31: 2713-2719, 2014

28. Liu B, Zhou Z, Zhou W, Liu J, Zhang Q, Xia J, Liu J, Chen N, $\mathrm{Li} \mathrm{M}$ and Zhu R: Resveratrol inhibits proliferation in human colorectal carcinoma cells by inducing G1/S-phase cell cycle arrest and apoptosis through caspase/cyclin-CDK pathways. Mol Med Rep 10: 1697-1702, 2014.

29. Androutsopoulos VP, Mahale S, Arroo RR and Potter G: Anticancer effects of the flavonoid diosmetin on cell cycle progression and proliferation of MDA-MB 468 breast cancer cells due to CYP1 activation. Oncol Rep 21: 1525-1528, 2009.

30. Androutsopoulos VP and Spandidos DA: The flavonoids diosmetin and luteolin exert synergistic cytostatic effects in human hepatoma HepG 2 cells via CYP1A-catalyzed metabolism, activation of JNK and ERK and P53/P21 up-regulation. J Nutr Biochem 24: 496-504, 2013.

31. Li G, Ma R, Huang C, Tang Q, Fu Q, Liu H, Hu B and Xiang J: Protective effect of erythropoietin on beta-amyloid-induced PC12 cell death through antioxidant mechanisms. Neurosei Lett 442: 143-147, 2008 .

32. Hao C, Gao L, Zhang Y, Wang W, Yu G, Guan H, Zhang L and Li C: Acetylated chitosan oligosaccharides act as antagonists against glutamate-induced pc12 cell death via bcl-2/bax signal pathway. Mar Drugs 13: 1267-1289, 2015.

33. Cheng Y, Ren X, Hait WN and Yang JM: Therapeutic targeting of autophagy in disease: Biology and pharmacology. Pharmaco Rev 65: 1162-1197, 2013.

34. Lorenzi PL, Claerhout S, Mills GB and Weinstein JN: A curated census of autophagy-modulating proteins and small molecules: Candidate targets for cancer therapy. Autophagy 10: 1316-1326, 2014.

35. Zhong W, Zhu H, Sheng F, Tian Y, Zhou J, Chen Y, Li S and Lin J: Activation of the MAPK11/12/13/14 (p38 MAPK) pathway regulates the transcription of autophagy genes in response to oxidative stress induced by a novel copper complex in HeLa cells. Autophagy 10: 1285-1300, 2014

36. Pan X, Zhang X, Sun H, Zhang J, Yan M and Zhang H: Autophagy inhibition promotes 5 -fluorouraci-induced apoptosis by stimulating ROS formation in human non-small cell lung cancer A549 cells. PLoS One 8: e56679, 2013.
37. Sui X, Chen R, Wang Z, Huang Z, Kong N, Zhang M, Han W, Lou F, Yang J, Zhang Q, et al: Autophagy and chemotherapy resistance: A promising therapeutic target for cancer treatment. Cell Death Dis 4: e838, 2013.

38. Yu L, Alva A, Su H, Dutt P, Freundt E, Welsh S, Baehrecke EH and Lenardo MJ: Regulation of an ATG7-beclin 1 program of autophagic cell death by caspase-8. Science 304: 1500-1502, 2004.

39. Amaravadi RK and Thompson CB: The roles of therapy-induced autophagy and necrosis in cancer treatment. Clin Cancer Res 13 7271-7279, 2007

40. Yuan J, Lei Z, Wang X, Zhu F and Chen D: Ruthenium complex $\Lambda$-WH0402 induces hepatocellular carcinoma LM6 (HCCLM6) cells death by triggering Beclin-1-dependent autophagy pathway. Metallomics 7: 896-907, 2015.

41. Xia J, Guo S, Fang T, Feng D, Zhang X, Zhang Q, Liu J, Liu B, Li M and Zhu R: Dihydromyricetin induces autophagy in HepG2 cells involved in inhibition of mTOR and regulating its upstream pathways. Food Chem Toxicol 66: 7-13, 2014.

42. Niu NK, Wang ZL, Pan ST, Ding HQ, Au GH, He ZX, Zhou ZW, Xiao G, Yang YX, Zhang X, et al: Pro-apoptotic and pro-autophagic effects of the Aurora kinase A inhibitor alisertib (MLN8237) on human osteosarcoma U-2 OS and MG-63 cells through the activation of mitochondria-mediated pathway and inhibition of $\mathrm{p} 38 \mathrm{MAPK} / \mathrm{PI} 3 \mathrm{~K} / \mathrm{Akt} / \mathrm{mTOR}$ signaling pathway. Drug Des Devel Ther 9: 1555-1584, 2015.

43. Shi L, Zhang T, Liang X, Hu Q, Huang J, Zhou Y, Chen M, Zhang Q, Zhu J and Mi M: Dihydromyricetin improves skeletal muscle insulin resistance by inducing autophagy via the AMPK signaling pathway. Mol Cell Endocrinol 409: 92-102, 2015.

44. Shin JH, Min SH, Kim SJ, Kim YI, Park J, Lee HK and Yoo OJ: TAK1 regulates autophagic cell death by suppressing the phosphorylation of p70 S6 kinase 1. Sci Rep 3: 1561, 2013.

45. Zhang J, Ma K, Qi T, Wei X, Zhang Q, Li G and Chiu JF: P62 regulates resveratrol-mediated Fas/Cav-1 complex formation and transition from autophagy to apoptosis. Oncotarget 6: 789-801, 2014.

46. Jakhar R, Paul S, Bhardwaj $M$ and Kang SC: Astemizole-Histamine induces Beclin-1-independent autophagy by targeting p53-dependent crosstalk between autophagy and apoptosis. Cancer Lett 372: 89-100, 2016.

47. Rah B, ur Rasool R, Nayak D, Yousuf SK, Mukherjee D, Kumar LD and Goswami A: PAWR-mediated suppression of BCL2 promotes switching of 3-azido withaferin A (3-AWA)-induced autophagy to apoptosis in prostate cancer cells. Autophagy 11: 314-331, 2015.

48. Luo S and Rubinsztein DC: Apoptosis blocks Beclin 1-dependent autophagosome synthesis: An effect rescued by Bcl-xL. Cell Death Differ 17: 268-277, 2010.

49. Pattingre S, Tassa A, Qu X, Garuti R, Liang XH, Mizushima N, Packer M, Schneider MD and Levine B: Bcl-2 antiapoptotic proteins inhibit Beclin 1-dependent autophagy. Cell 122: 927-939, 2005 